\title{
PENGEMBANGAN MODEL PEMBELAJARAN KOMUNITAS SOSIAL BERBASIS LIERASI BAHASA DALAM PENULISAN BUKU TEKS
}

\author{
Khaerudin Kurniawan \\ Universitas Pendidikan Indonesia \\ e-mail: khaerudinkurniawan@upi.edu
}

\begin{abstract}
Penelitian ini dilatarbelakangi oleh tuntutan kemampuan berpikir dan kompetensi komunikasi abad 21, literasi sebagai budaya pembelajaran, dan kompleksitas penulisan akademik di perguruan tinggi. Tujuan penelitian ini adalah merancang dan mengembangkan model Social Community Learning (SCL) berbasis literasi bahasa dalam pembelajaran menulis buku teks. Metode yang digunakan dalam penelitian ini adalah model Design Based Research (DBR) Reeves. Mahasiswa FPBS Bahasa dan Sastra Indonesia Universitas Pendidikan Indonesia angkatan 5C tahun ajaran 2014/2015 serta mahasiswa kelas 5A dan dan 5B tahun ajaran 2017/2018 dijadikan sebagai subjek penelitian. Temuan dari penelitian ini adalah: pertama, model baru SCL berbasis literasi bahasa mampu menjawab permasalahan pembelajaran abad 21, yaitu mengembangkan empat kompetensi pembelajaran (kemampuan pemahaman tinggi, kemampuan berpikir kritis, kemampuan berkolaborasi, dan komunikasi). Kedua, model SCL mampu menciptakan interaksi yang efektif, lingkungan belajar yang lebih terbuka, budaya akademik yang positif, dan memicu siswa untuk berpikir terbuka dengan cara berbagi masalah, informasi, pengalaman, dan pemecahan masalah. Ketiga, adanya pedoman penulisan buku teks sebagai acuan siswa dan komunitas sosial lainnya dalam menulis buku teks.
\end{abstract}

Keywords : Model pembelajaran komunitas social, literasi bahasa, buku teks

\section{Pendahuluan}

Kemampuan berliterasi (membaca dan menulis) merupakan hal yang sangat diperlukan bagi kalangan akademisi. Graham dan Tracey (2016) mengemukakan bahwa menulis adalah keterampilan yang sangat penting dimiliki oleh pemelajar. Tanpa kemampuan menulis, pemelajar akan sulit mengikuti pembelajaran. Menulis adalah keterampilan berbahasa yang paling sulit dan kompleks (Lerner dalam Goddard dan Carole, 2008). Kompleksitas menulis terletak pada tuntutan kemampuan mengorganisasikan ide secara logis dan runtut, serta menyajikannya dalam ragam bahasa tulis yang baik, benar dan komunikatif. Hal ini sejalan dengan pandangan Graham \& Harris (1988), bahwa menulis dikatakan sebagai kegiatan yang kompleks karena belajar menulis lebih jauh melibatkan pengetahuan dan kemampuan berbahasa lainnya.

Pemberian mata kuliah menulis buku teks pada mahasiswa kependidikan perlu dilakukan. Pendidik (guru) harus memiliki tanggung jawab dalam membantu proses pembelajaran. James M. Cooper (1990) menyatakan bahwa guru adalah orang yang dibebani dengan tanggung jawab untuk membantu siswa dalam proses 
pembelajaran. Guru/calon guru perlu memiliki kemampuan khusus, kemampuan tersebut tidak mungkin dimiliki oleh orang lain yang bukan guru. Kemampuan tersebut mengantarkan guru sebagai profesi yang memerlukan keterampilan khusus hasil proses pendidikan oleh lembaga pendidikan keguruan. Hal ini seperti diungkapkan oleh Greta G. Morine-Dershimer (dalam James M. Cooper, 1990), guru adalah seseorang yang memiliki pengetahuan khusus dan kemampuan produktif yang cocok diaplikasikan dalam berbagai situasi.

Penelitian ini mengusung beberapa permasalahan dan fokus penelitian, yaitu: (1) kompleksnya kegiatan menulis, khususnya menulis akademik, (2) kurangnya minat baca dan literasi bahasa di kalangan akademisi, (3) pembelajaran menulis akademik masih bersifat guru sentris yang kurang inovatif dalam mengembangkan model pembelajaran, (4) proses pembelajaran belum selaras dengan kompetensi belajar, yaitu kemampuan untuk berkolaborasi dan berkomunikasi, dan (5) perlu adanya desain model pembelajaran komunitas sosial berbasis literasi bahasa dalam pembelajaran menulis akademik (buku teks).

\section{Metode}

Metode yang digunakan dalam penelitian ini adalah Design Based Research (DBR). Menurut Cobb (dalam Bakker, 2004), istilah penelitian design research dimasukkan ke dalam penelitian pengembangan (developmental research) karena berkaitan dengan pengembangan materi dan bahan pembelajaran. Penelitian ini menggunakan desain model penelitian Reeves. Desain penelitian Design Based Research $(D B R)$ model Reeves dapat dilihat sebagai berikut.

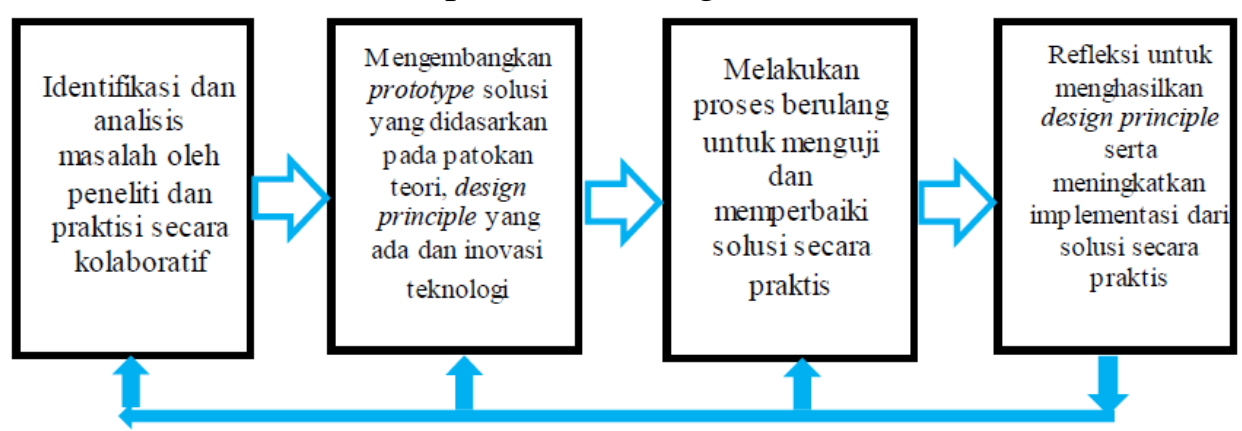

\section{Gambar 1}

\section{Desain Penelitian Model Reeves}

\section{Hasil dan Pembahasan}

Adapun desain model yang telah dirancang sebagai berikut. 


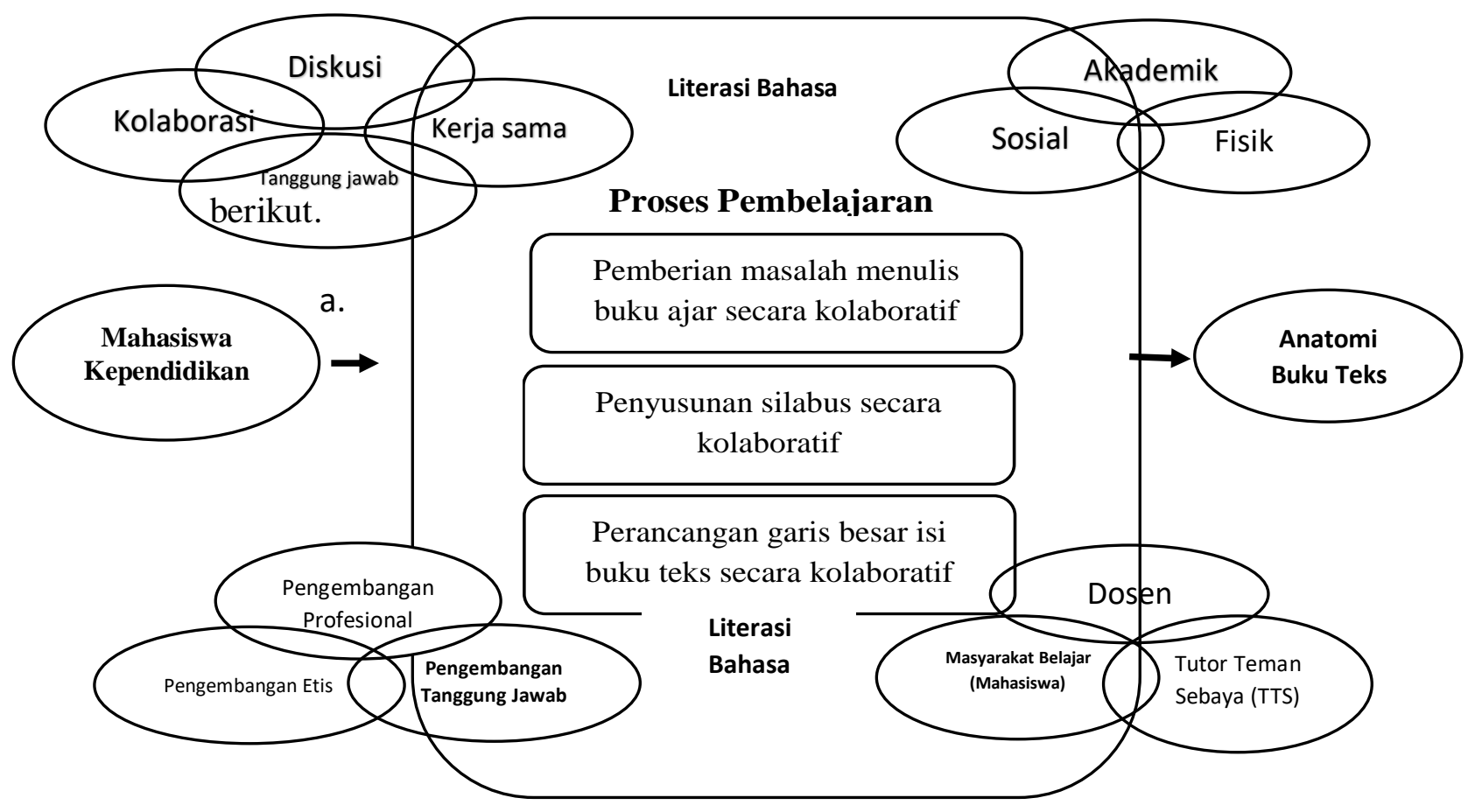

Gambar 2

\section{Desain Model Makro 1}

Model PKS berbasis literasi bahasa pada Desain Makro I masih dalam tahap bagaimana menulis draf atau anatomi buku teks. Berdasarkan gambaran model tersebut, Model PKS memiliki 4 prinsip yang selalu menjadi ciri khas dan kultur dalam proses pembelajarannya.

Adapun desain model makro 2 yang telah disiapkan adalah sebagai berikut.

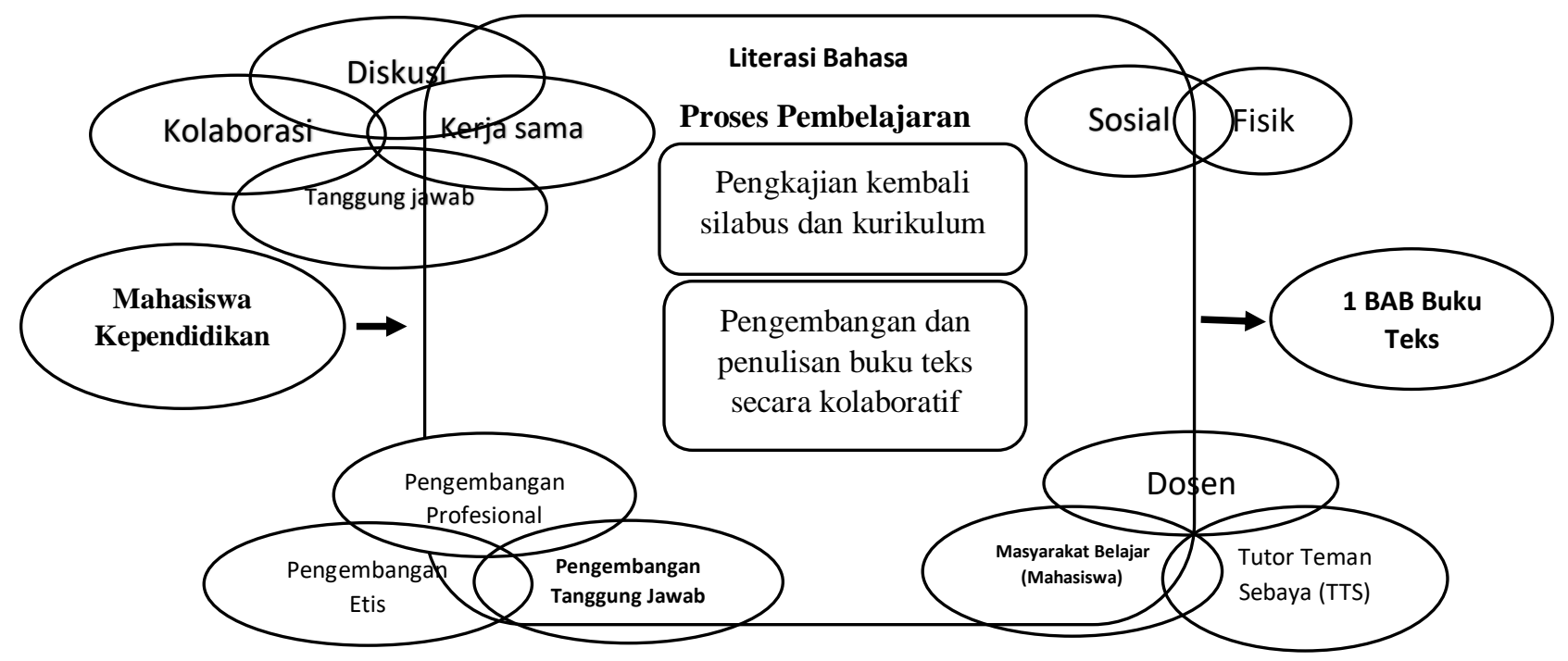




\section{Gambar 3}

\section{Desain Model Makro 2}

Adapun desain model makro 3 yang telah dirancang adalah sebagai berikut.

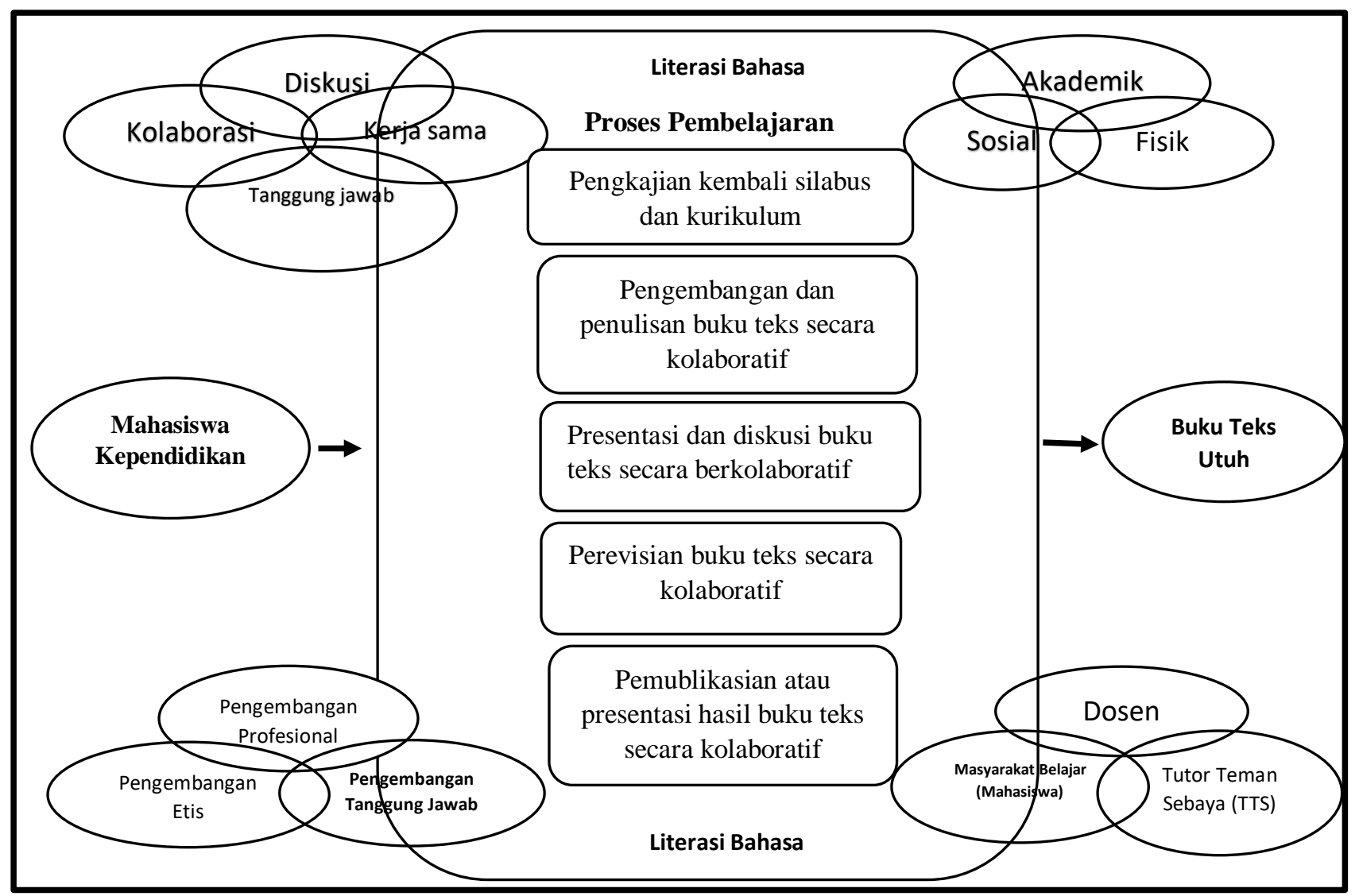

Gambar 4

\section{Desain Model Makro 3}

Model Pembelajaran Komunitas Sosial berbasis literasi bahasa pada pembelajaran menulis buku teks pada Desain Makro III sudah menyusun 1 buku teks secara utuh.

Berdasarkan hasil penelitian dan refleksi ketiga desain makro dalam mengimplementasikan model PKS berbasis literasi bahasa pada pembelajaran menulis buku teks dan penilaian terhadap model, maka dapat dibuat model akhir yang relevan untuk meningkatkan kemampuan mahasiswa dalam menulis buku teks. Model tersebut digambarkan sebagai berikut. 
Rancangan Akhir Model Pembelajaran Komunitas Sosial Berbasis Literasi Bahasa dalam Pembelajaran Menulis Buku Teks

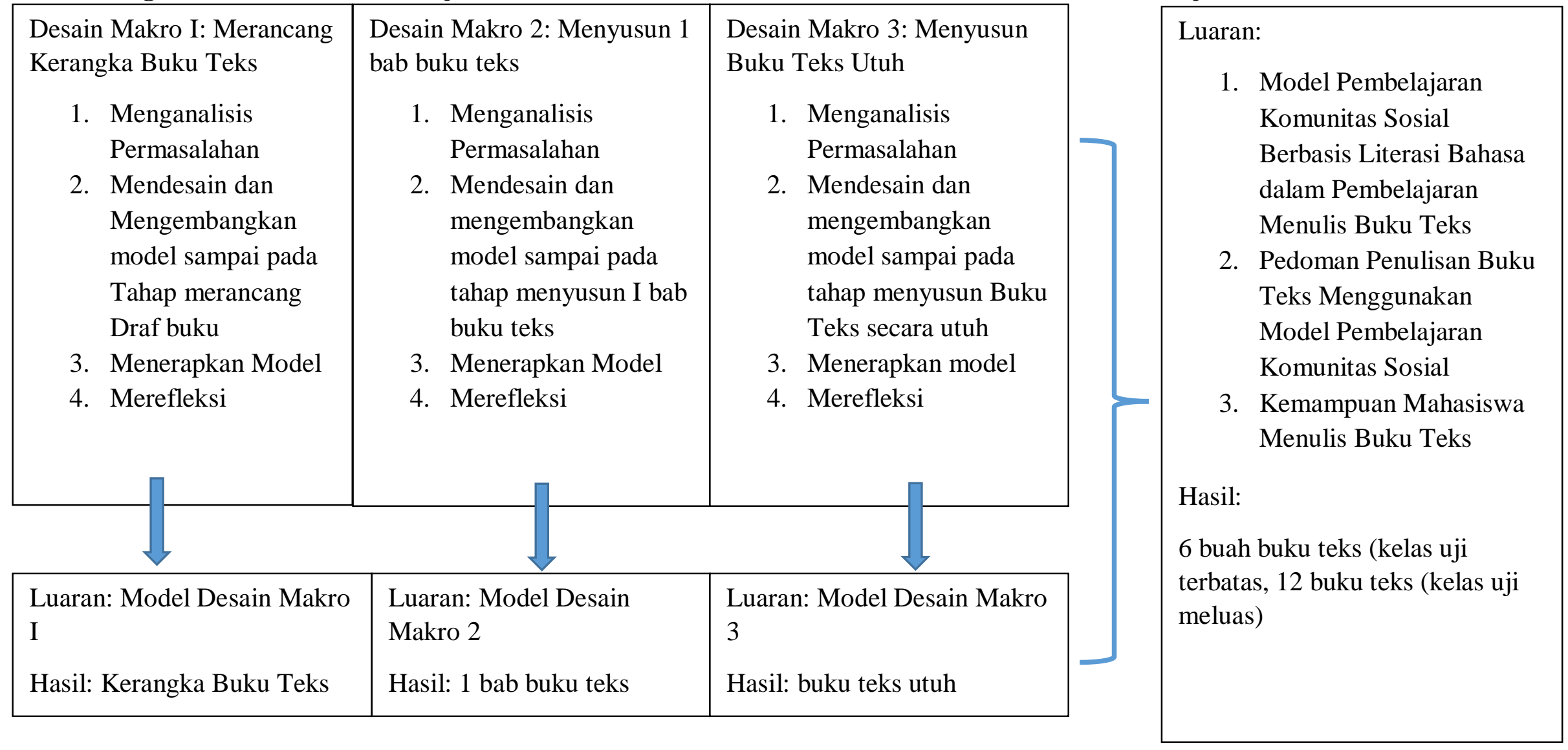




\section{Simpulan}

Temuan yang dihasilkan dalam penelitian ini adalah sebagai berikut: (a) luaran berupa model baru pembelajaran komunitas sosial berbasis literasi bahasa, (b) pedoman penulisan buku teks berbasis literasi bahasa, (c) hasilnya berupa naskah buku teks sebanyak 18 buah (6 buah dihasilkan dari kelas uji terbatas dan 12 buah dari kelas uji meluas). Buku-buku teks yang dihasilkan dari penelitian ini layak diusulkan penilaiannya ke lembaga berwenang (Badan Pengembangan Bahasa dan Perbukuan) sehingga buku-buku tersebut dapat dimanfaatkan dalam pembelajaran bahasa Indonesia di jenjang sekolah (SMP/MTs, SMA/MA/SMK).

\section{Ucapan Terima Kasih}

Terima kasih penulis sampaikan kepada Direktorat Jenderal Pendidikan Tinggi yang telah mendanai riset disertasi doktor ini sehingga penulis dapat menyelesaikan studi S-3 sesuai dengan rencana.

\section{Referensi}

Bakker, A. (2004). Design research in statistics education: On symbolizing and computer tools. Desertasi Doktor pada Utrech University : Tidak diterbitkan.

Bakker, A. \& Van Eerde, H. A. A. (in press). An introduction to designbased research with an example from statistics education. in a. bikner-ahsbahs, c. knipping, \& n. presmeg (eds.), doing qualitative research: methodology and methods in mathematics education. New York: Springer.

Barkley, E. F., Cross, K. P. \& Major, C. H.. (2005). Collaborative learning techniques. San Francisco: Jossey-Bass.

Brower Aaron M., dan Karen M. Dettinger. (1998). What is a learning community?: toward a comprehensive model. About Campus, vol. 3, 5: pp. 15-21. , First Published Nov 1, 1998. http://journals.sagepub.com/doi/full/10.1177/108648229800300504

Bruder, M. N. \& Furey R. R. (2012). The writing segment of an intensive program for students of english as a second language, Pittsburgh: University of Pittsburgh.

Burden, Paul, R. dan Byrd, David, M. (1999). Methods for effective teaching $\left(2^{\text {nd }}\right.$ ed). Needham Heights: Allyn and Bacon AA Viacom Company.

Furneaux, B. (1995). Theoretical constructs and relationship in information systems research. USA: Information Science Reference (an imprint of IGI Global).

Goddard, Y. L. \& Carole S. (2008). Effects of self-monitoring on the narrative and expository writing of four fourth-grade students with learning disabilities. Reading \& Writing Quarterly, Vol. 24, hlm. 408-433.

Graff, Harvey J. (2006). Literacy. Microsoft@ $\quad$ Encarta® [DVD]. Redmond, WA: MicrosoftCorporation 2005.

Graham, S. \& Harris, K. R. (1988). Instructional recommendations for teaching writing to exceptional students. exceptional children, Vol. 54, hlm. 506-512.

Graham, S. \& Tracey E. (2016). Writing and writing difficulties from primary grades to college: introduction to the special issue. Learning Disability Quarterly, Vol. 39 (1), hlm. 3-4.

Hale, G., Taylor, C., Bridgeman, J., Carson, J., Kroll, B., \& Kantor, R. (1996). A study of writing tasks assigned in academic degree programs. Princeton, NJ: Educational Testing Service. 